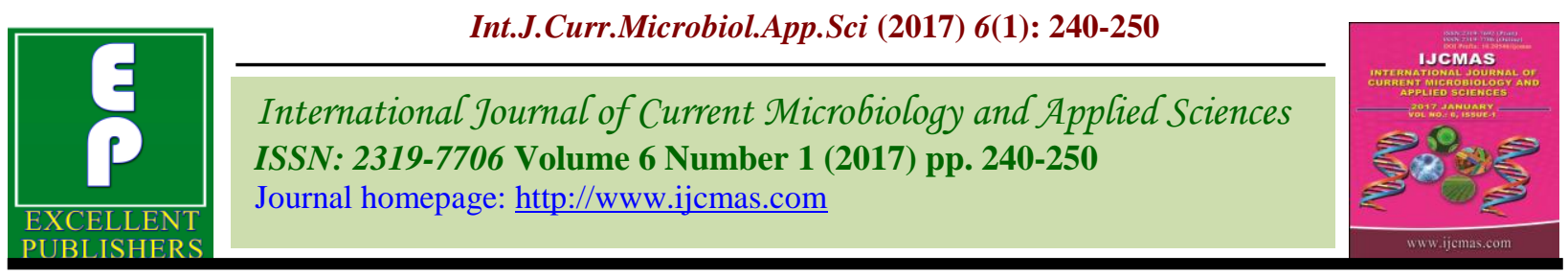

Review Article

http://dx.doi.org/10.20546/ijcmas.2017.601.029

\title{
Vulvovaginal Candidosis
}

\author{
A. Hodiwala Bhesania ${ }^{1 *}$ and A. Narayankhedkar ${ }^{2}$ \\ ${ }^{1}$ Department of Microbiology, MGM Medical College and Hospital, Kamothe, \\ Navi Mumbai, India \\ ${ }^{2}$ Manager Medical Services, Suburban Diagnostic Pvt Ltd, India \\ *Corresponding author
}

\section{A B S T R A C T}

\begin{tabular}{l} 
Ke y w o r d s \\
Vulvovaginal \\
Candidosis \\
(VVC), \\
C.albicans. \\
\hline
\end{tabular}

Article Info

Accepted:

12 December 2016

Available Online:

10 January 2017
Vulvovaginal candidiasis is the name often given to Candida albicans infection of the vagina associated with a dermatitis of the vulva (an itchy rash). 'Vaginal thrush', 'monilia', and vulvovaginal candidosis are other names used for vulvovaginal candidiasis. About $20 \%$ of non-pregnant women aged 15 to 55 harbour Candida albicans in the vagina. Most have no symptoms and it is harmless to them. Overgrowth of Candida albicans causes a heavy white curd-like vaginal discharge, a burning sensation in the vagina and vulva and/or an itchy rash on the vulva and surrounding skin. Oestrogen causes the lining of the vagina to mature and to contain glycogen, a substrate on which Candida albicans thrives. Lack of oestrogen in younger and older women makes vulvovaginal candidiasis much less common. The most common symptom is vaginal itching, which may be severe. Other symptoms include burning with urination, white and thick vaginal discharge that typically does not smell bad, pain with sex, and redness around the vagina. Symptoms often worsen just before a woman's period. Vaginal yeast infections are due to excessive growth of Candida. These yeast are normally present in the vagina in small numbers. It is not classified as a sexually transmitted infection; however, it may occur more often in those who are frequently sexually active. Risk factors include taking antibiotics, pregnancy, diabetes, and HIV/AIDS. Eating a diet high in simple sugar may also play a role. Tight clothing, type of underwear, and personal hygiene do not appear to be factors. Diagnosis is by testing a sample of vaginal discharge. As symptoms are similar to that of the sexually transmitted infections, chlamydia and gonorrhea, testing may be recommended. About $75 \%$ of women have at least one vaginal yeast infection at some point in their lives while nearly half have at least two. About 5\% have more than three infections in a single year. It is the second most common cause of vaginal inflammation after bacterial vaginosis.

\section{Introduction}

VVC is an extremely common infection in women of childbearing age of all strata of society. Since it has now been excluded from the ranks of sexually transmitted diseases and is also not a notifiable disease, not much information regarding its incidence and epidemiology is available (Jindal et al., 2006).

\section{History}

The first known description of Candida infection, oral candidiasis (thrush) in two patients with other underlying disease, may be found in Hippocrates" "Epidemics" from the fourth century BC. The first descriptions of 
thrush in modern medicine were made by Rosen von Rosenstein in1771 and by Underwood in1784, who identified the infection as a pediatric problem and accordingly described it in books dealing with such entities. Lagenback, in 1839, described the fungus in as case of oral thrush observed in a patient suffering from typhus, he misidentified it as the causative agent of the underlying disease. The correct association between oral thrush and the fungus was made in 1842 by Gruby who classified the microorganism as Sporotichum. During the following decades various pathological conditions were shown to be associated with yeasts. The fungus was isolated by Bennett in 1844 in the sputum of tuberculotic patient, by Wilkinson in 1849 from vaginal candidiasis, by Robin in 1853 from a systemic infection and by Zenker in 1861 from brain infection in a debilitated patient in whom the fungus spread hematogenously from an oral infection. In 1875, Hausemann established the possibility of infant infection during birth by demonstrating the analogy between the causative agent of oral and vaginal thrush.Castellani, in1912, while describing 'tea tasters' cough, was probably the first to suggest the possibility that Candida species other than C.albicans may be involved in pathological processes. The nomenclature of yeast isolated from patients, changed often. Robin in1853 named it Oidium albicans, Quinquad in1868 Syringospora robinii and Rees in 1875 Saccharomyces albicans. Mycological studies by Grawitz, published in 1877, described the various morphological forms of Candida. The first binomial to gain wide acceptance over a long period, and which is still used, albeit wrongly, was Monilia albicans, which was suggested by Zopf in 1890. Berkhout, in 1923 after recognizing the differences between Monilia spp isolated from rotting plants and fruit and those isolated from medical cases, established the genus Candida to accommodate the latter.
This was accepted as the official name of the genus by the Eighth Botanical Congress in Paris in 1954.

\section{Epidemiology}

Information on the incidence of vulvovaginal candidosis is incomplete, since the disease is not a reportable entity and data collection is hampered by inaccuracies of diagnosis and the use of non-representative study populations (Jack et al., 2007). The infection-caused by Candida spp-affects $70-75 \%$ of women at least once during their lives, most frequently young women of childbearing age. $40-50 \%$ of women will experience a recurrence. 5-8\% of adult women have recurrent vulvovaginal candidosis, defined as four or more episodes every year (Foxman et al., 1998). In one study (Cormack, 1994), almost 30\% of the women with symptoms of vulvovaginitis had yeast isolated, confirming the diagnosis of vulvovaginal candidosis. Other authors indicate that vulvovaginal candidosis is responsible for $15-30 \%$ of vulvovaginal symptoms. Unfortunately; the availability of over-the-counter antimycotics will further limit the ability to measure asymptomatic candida carriage and vulvovaginal candidosis. The prevalence of VVC varies from $10 \%$ to $30 \%$ in various studies in India (Anis Ahmad et al., 2009; Bang et al., 1989). Candida albicans is responsible for 80 to 92 percent of episodes of vulvovaginal candidiasis. Recently, an increased frequency of other candida species, particularly C.glabrata, has been reported (Jack et al., 1997). In many parts of the world, non-albicans isolatesnotably $C$ glabrata- affect $10-20 \%$ of women. Vaginitis induced by non-albicans species is clinically indistinguishable from that caused by C.albicans; moreover, such species are often more resistant to treatmen (Odds, 1988; Bauters et al., 2002). Nonalbicans Candida spp-especially $C$ 
glabrata - often cause recurrent vulvovaginal candidosis. The incidence of vulvovaginal candidosis caused by non-albicans strains is thought to be increasing because of singledose treatment, low-dosage azole maintenance regimens, and the use of overthe-counter antimycotics.

\section{Microbiology}

Candida species are normal flora of skin and vagina. Candida species may be isolated from $20 \%$ of asymptomatic healthy women (Centers for Disease Control and Prevention). Candida organisms gain access to the vaginal lumen and secretions mainly from the adjacent perianal area (Bertholf, 1983). Effective anti-candida defence mechanisms in the vagina allow long-term persistence of candida organisms as vaginal commensals in an avirulent phase. Candida can be either a commensal organism or a pathogen in the vagina, and dogma dictates that changes in the host vaginal environment are necessary before the organism induces pathological effects.

\section{Risk factors}

Although vulvovaginal candidosis is monomicrobial, causation is multifactorial. Recurrent vulvovaginal candidosis can be idiopathic or caused by several different mechanisms. Factors that predispose to vaginal colonisation can differ from those that facilitate transformation from asymptomatic colonisation to symptomatic vaginitis.

\section{Candida virulence factors}

\section{Adhesins}

Colonisation of the vagina requires yeast adherence to vaginal epithelial cells. $C$ albicans adheres in significantly higher numbers to such cells than do non-albicans species (King et al., 1980). All C.albicans strains seem to adhere equally well to both exfoliated vaginal and buccal epithelial cells. By contrast, there is considerable person-toperson variation in in-vitro vaginal epithelial cell receptivity to candida organisms in adherence assays (Sobel et al., 1981). However; no increased receptivity has been reported in women with recurrent infections. Yeast surface mannoprotein serves as adhesions.

\section{Phenotypic switching}

The phenotypic switching denotes the ability of organisms of single strain to switch reversibly at high frequencies among different colony phenotypes. Due to this ability, it can grow in variety of morphological forms ranging from unicellular budding yeast (blastospore) to filamentous pseudohyphae and true hyphae. Such switching could enable adaptation to different or changing conditions in the host's defense system. High-frequency heritable switching occurs in colony morphology of most Candida spp grown on aminoacid rich agar at $24^{\circ} \mathrm{C}$ (Slutsky et al., 1985). The variant phenotypes show a varying capacity to form mycelia spontaneously and express other virulence factors, including drug resistance and adherence. There is insufficient evidence that phenotypic switching occurs in vivo at $37^{\circ} \mathrm{C}$; however, this is an attractive hypothesis to explain spontaneous in-vivo transformation from asymptomatic colonisation to symptomatic vaginitis. Fresh clinical vaginal isolates obtained during acute vaginitis have been found to be in a high-frequency mode of switching. These multiple phenotypes are derived from the same or related genetic strains.

\section{Enzymes and Toxins}

Virulence is enhanced by proteolytic enzymes, toxins, and phospholipase 
elaborated by yeast.Extracellular hydrolases such as proteinases and phospholipases are major facilitators of host tissue invasion and of the disease process that ensues (Mane et $a l .$, 2012). Secreted aspartyl proteinases elaborated by pathogenic Candida spp have been identified in vaginal secretions in women with symptomatic vaginitis but not in those with asymptomatic colonisation. These proteolytic enzymes, with broad substrate specificity, destroy free and cell-bound proteins that impair fungal colonisation and invasion. Several genes that govern proteinase production (SAP1, SAP2, and SAP3) have been cloned, and a strong correlation exists both in vitro and in experimental vaginitis between gene expression, aspartyl proteinase secretion, and the ability to cause disease (Taylor et al., 2005; Naglik et al., 2003; Schaller et al., 2003). Extracellular phospholipases are also considered a key attribute that aid invasion of the host mucosal epithelia. They are thought to contribute to virulence by lysing host cells or altering their surface characteristics so that adherence and penetration are facilitated. Mycotoxinincluding a gliotoxin identified in the vagina-could act to inhibit phagocytic activity or suppress the local immune system (Shah et al., 1995). Iron binding by candida organisms has also been reported to facilitate yeast virulence. The ability of Candida to acquire elemental iron through haemolysin production is pivotal to its survival and ability to establish infections in humans, in particular in disseminated candidiasis.

\section{Clinical features (Centers for Disease Control and Prevention)}

- Vulvar pruritis is the commonest symptom

- Thick, white, curdy ("cottage cheese-like") vaginal discharge.

- Erythema, irritation, occasional erythematous "satellite" lesion

- External dysuria and dyspareunia

\section{Diagnosis}

Visualization of pseudohyphae (mycelia) and/or budding yeast (conidia) on $10 \% \mathrm{KOH}$ wet prep examination (preferred), saline wet mount, or Gram stain.

pH: normal (4.0 to 4.5 ). If $\mathrm{pH}$ is abnormally high $(\geq 4.5)$, consider concurrent bacterial vaginosis $(\mathrm{BV})$ or trichomoniasis.

Fungal culture: Vaginal swabs can be cultured on Sabouraud dextrose agar with antibacterial antibiotics and incubated at 250C and 370C. The colonies appear in 3-4 days and are cream colored, smooth and pasty. Sometimes growth may be observed after an overnight incubation as well. A secondary smear is prepared from a single isolated colony and stained by Gram method.

\section{Germ tube test (Chander, 2011)}

This procedure is used for presumptive identification of Candida species. The culture of Candida is treated with sheep or normal human serum and incubated at 370C for 2$4 \mathrm{hrs}$.A drop of suspension is examined on the slide under microscope. The germ tubes are seen as long tube-like projections extending from the yeast cells. There is no constriction at the point of attachment to the yeast cell as seen in pseudohyphae. The germ tubes are found in two hours in C.albicans and C.dublinensis not in other species of this genus. The demonstration of the germ tube is also known as Reynolds-Braude Phenomenon.

\section{Chlamydospore formation}

The suspected strain of the Candida isolates is grown on cornmeal agar (CMA) and incubated at 250C.It shows large highly refractile, thick walled, terminal chlamydospores after 2 to 3 days of incubation. 


\section{Biochemical tests}

Tests like sugar fermentation and sugar assimilation are of immense importance for identification of yeast isolates.

Assimilation tests have largely replaced fermentation as a means of species identification in view of equivocal fermentation test results. The method consists of essentially growing yeast on a basal carbohyhdrate-free medium supplemented with test sugar. There are many variations on the number of sugars and the method of their application to the basal medium.

Several packaged yeast identification systems e.g. API 20 C AUX (BioMerieux, France) which consists of 20 cupules containing dehydrated substrates which enable the performance of 19 assimilation tests. The cupules are inoculated with semisolid minimal medium. The yeasts will only grow if they are capable of utilizing each substrate as sole source of carbon. The reactions are read by comparing them to growth controls. Identification is obtained by referring to the Analytical Profile Index or using the identification software as per manufacturer's instructions.

(BioMerieux, France).

\section{CHROM agar Candida}

CHROM agar Candida is a rapid plate-based test for the simultaneous isolation and identification in various Candida species. This medium distinguishes different Candida species by color as a result of biochemical reactions. This can be used for simultaneous isolation and presumptive identification of various Candida species like C.albicans, C.krusei, C.tropicalis,

C.glabrata, C.parapsilosis and C.dublinensis. It is possible to the principal yeast species by their morphological characteristics within 24 hours and to isolate pathogenic fungi within 24-48 hours. This is based on the direct detection of specific enzymatic activities by adding certain substrates of fluorochromes to the media.

Candida albicans produces an enzyme beta$\mathrm{N}$-acetyl- galactosaminidase and incorporation of chromogenic or fluorogenic hexosaminidase substrates into the growth medium helps in identification of C.albicans isolates directly on primary isolation. HiCrome Candida Differential Agar, Modified is a selective and differential medium, which facilitates rapid isolation of yeasts from mixed cultures and allows differentiation of Candida species namely C.albicans, C.krusei, C.tropicalis and C.glabrata on the basis of coloration and colony morphology. On this medium results are obtained within 48 hours and it is useful for the rapid and presumptive identification of common yeasts in Mycology and Clinical Microbiology Laboratory. Peptone special and yeast extract provides nitrogenous, carbonaceous compounds and other essential growth nutrients. Phosphate buffers the medium well. Chloramphenicol suppresses the accompaning bacterial flora. C.albicans appear as light green coloured smooth colonies, C.tropicalis appear as blue to metallic blue coloured raised colonies. C.glabrata colonies appear as cream to white smooth colonies, while C. krusei appear as purple fuzzy colonies. Cultural characteristics observed with added HiCrome Candida Selective Supplement (FD192), after an incubation at $30^{\circ} \mathrm{C}$ for $40-48$ hours (Himedia laboratories, Mumbai). There is no reliable serological or antigen detection technique available for the diagnosis of vulvovaginal candidiasis. Because most clinicians are unable or unwilling to measure vaginal $\mathrm{pH}$ and do microscopy, most women with vulvovaginal symptoms remain incorrectly 
diagnosed and treated. PCR detection of Candida spp in vaginal samples is possible but is not available as a diagnostic test and might not prove to be a clinically useful test (Trama et al., 2005).

\section{Management}

Classification of VVC: Uncomplicated or Complicated Uncomplicated VVC includes sporadic or infrequent vulvovaginal candidiasis, mild-tomoderate vulvovaginal candidiasis, or vulvovaginal candidiasis in nonimmunocompromised women.

Complicated VVC includes recurrent vulvovaginal candidiasis (RVVC), severe vulvovaginal candidiasis, nonalbicans candidiasis, or vulvovaginal candidiasis in women with uncontrolled diabetes, debilitation, or immunosuppression.

\section{I.Uncomplicated VVC}

Mild to moderate signs and symptoms

Sporadic, nonrecurrent disease in a normal host with normally susceptible

C. albicans.

$75 \%$ of women have at least one lifetime episode.

Responds to all azole treatment regimens including short (three-day) and single-dose oral and vaginal therapy.

\section{CDC-Recommended Treatment Regimens for Uncomplicated VVC}

Intravaginal Agents :

Clotrimazole $2 \%$ cream $5 \mathrm{~g}$ intravaginally for 3 days or

Miconazole $2 \%$ cream $5 \mathrm{~g}$ intravaginally for 7 days or
Miconazole $4 \%$ cream $5 \mathrm{~g}$ intravaginally for 3 days or

Miconazole $100 \mathrm{mg}$ vaginal suppository, 1 suppository for 7 days or

Miconazole $200 \mathrm{mg}$ vaginal suppository, 1 suppository for 3 days or Prescription Oral agent

Fluconazole $150 \mathrm{mg}$ oral tablet, 1 tablet in a single dose

\section{Complicated VVC}

Approximately $10 \%$ to $20 \%$ of women with candidiasis will have complicated VVC. VVC is considered complicated when the following exists.

Recurrent VVC (RVVC)-four or more episodes in one year, consider getting culture to identify species and confirm diagnosis.

Severe VVC-Extensive vulvar erythema, edema, excoriation or fissure formation, long course recommended.

Nonalbicans species- Requires longer duration of treatment (10-15 days) with topical azoles.

Compromised host-Women with diabetes, immunosuppression, or HIV

\section{Complicated VVC Treatment}

\section{Recurrent VVC (RVVC)}

Seven to fourteen days of topical therapy, or $100 \mathrm{mg}, 150 \mathrm{mg}$, or $200 \mathrm{mg}$ oral dose of fluconazole every third day for a total of 3 doses (days 1, 4, and 7) While some women with RVVC have risk factors, most women do not. Recurrent disease may be more likely due to nonalbicans species.

After an initial intensive regimen of 7-14 days, a maintenance regimen for at atleast 6 months is recommended. 
Maintenance regimens - Fluconazole $100 \mathrm{mg}$, $150 \mathrm{mg}$ or Fluconazole $200 \mathrm{mg}$ orally weekly for 6 months or Clotrimazole $200 \mathrm{mg}$ twice a week topically or Clotrimazole $500 \mathrm{mg}$ dose vaginal suppositories once weekly

RVVC should be confirmed by culture before initiating maintenance therapy. VVC diagnosis should also be periodically reconfirmed, and the presence of other contributory causes (new trichomoniasis or BV) assessed.

Patients with RVVC who are receiving treatment should receive regular follow-up to monitor the effectiveness of therapy and the occurrence of drug side effects. Drug interactions with oral treatment may occur.

\section{Severe VVC}

Seven to fourteen days of topical therapy, or Fluconozole $150 \mathrm{mg}$ oral dose repeated in 72 hours.

In cases associated with severe vulvitis and intense pruritis, topical applications of lowpotency corticosteroid cream or nystatin cream may be beneficial.

\section{Non albicans VVC}

Optimal treatment unknown
Seven to fourteen days with a nonfluconazole therapy (oral or topical)

$600 \mathrm{mg}$ boric acid in gelatin capsule vaginally once a day for 14 days for recurrences

\section{VVC in a compromised host}

Seven to fourteen days of topical therapy

\section{VVC in pregnancy}

Fluconazole is contraindicated.

Seven day topical agents are recommended

\section{Vulvovaginal Candidiasis In Hiv-Positive Women}

Several studies have shown that vaginal colonisation with candida is increased in HIV-positive women compared with those who are HIV negative. Cross-sectional and cohort studies have shown only a moderate increase in Vulvovaginal candidosis in HIVpositive women not receiving antiretroviral therapy compared with HIVnegative women (Schuman et al., 1998; Sobel et al., 2001) and the increased incidence of vulvovaginal candidosis in HIV-positive women compared with HIV-negative women was modest compared with the increase in the occurrence of oropharyngeal candidosis.

Table.1 Fermentation reactions of Candida species

\begin{tabular}{|l|l|l|l|l|}
\hline Candida Sp & Glucose & Maltose & Sucrose & Lactose \\
\hline C.albicans & AG & AG & - & - \\
\hline C.tropicalis & AG & AG & AG & - \\
\hline C.kefyer & AG & AG & AG & - \\
\hline C.guilliermondii & AG & - & AG & - \\
\hline C.parapsilosis & AG & - & - & - \\
\hline C.krusei & AG & - & - & - \\
\hline C.glabrata & AG & - & - & - \\
\hline
\end{tabular}


Table.2 Assimilation reactions of different Candida species

\begin{tabular}{|l|l|l|l|l|l|l|l|l|l|}
\hline Candida spp. & $\mathrm{D}$ & $\mathrm{M}$ & $\mathrm{S}$ & $\mathrm{L}$ & $\mathrm{C}$ & $\mathrm{G}$ & $\mathrm{T}$ & $\mathrm{Me}$ & $\mathrm{X}$ \\
\hline C.albicans & + & + & + & + & + & + & + & - & + \\
\hline C.tropicalis & + & + & + & - & + & + & + & - & + \\
\hline C.parapsilosis & + & + & + & - & - & + & + & - & + \\
\hline C. krusei & + & - & - & - & - & - & - & - & + \\
\hline C.glabrata & + & - & - & - & - & - & + & - & + \\
\hline C.stellaroidea & + & + & - & - & - & + & + & - & + \\
\hline C.gulliermondii & + & + & + & - & + & + & + & + & + \\
\hline C.kefyr & + & - & + & + & + & + & - & - & + \\
\hline
\end{tabular}

D-Dextrose, M-Maltose, S-Sucrose, L-Lactose, C-Cellobiose, G-Galactose, T-Trehalose, Me-Melobiose, X-Xylose.

Fig.1 Risk Factors for Vulvovaginal Candidiasis

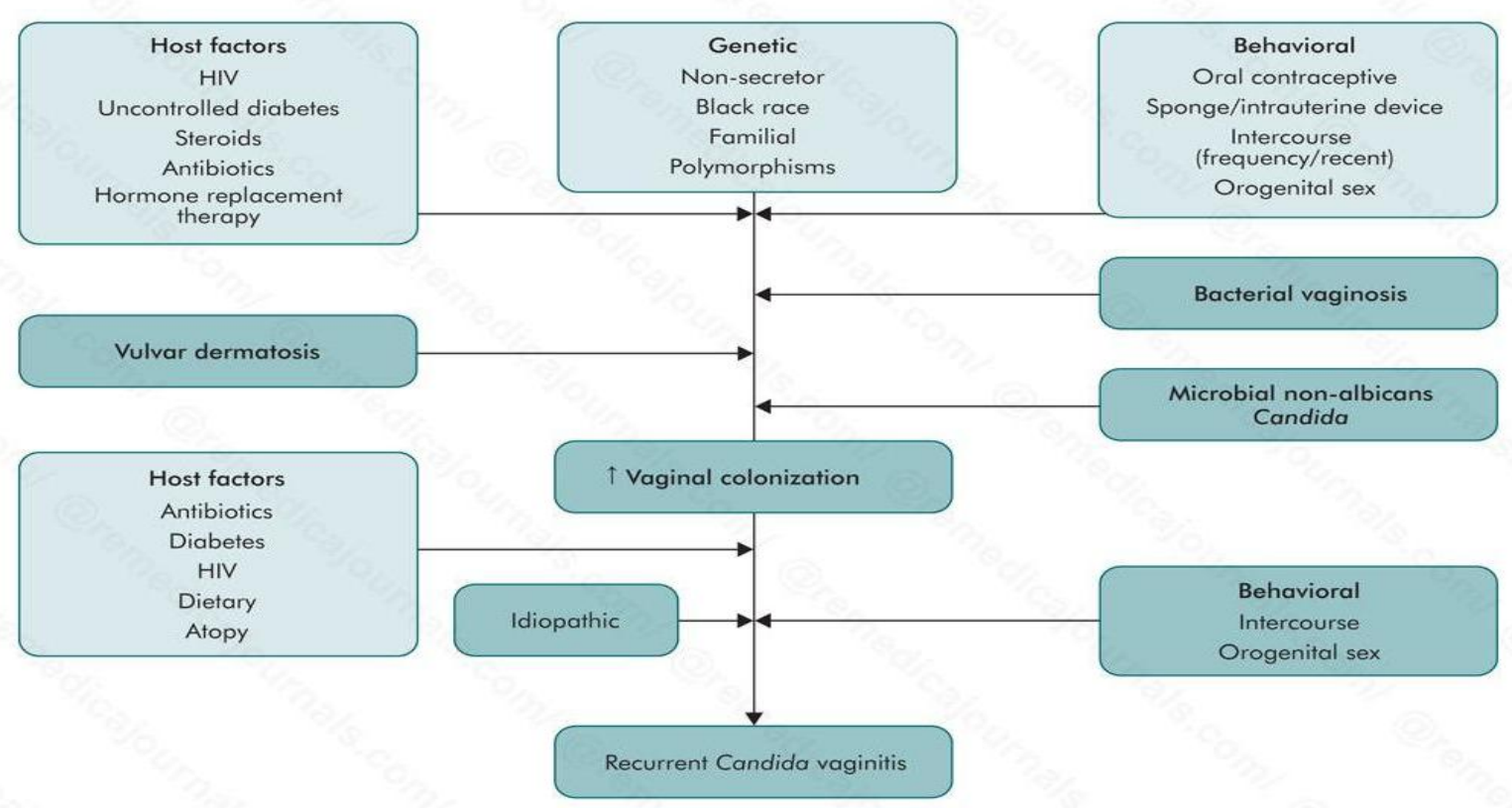

Fig.2 Vulvovaginal Candidiasis

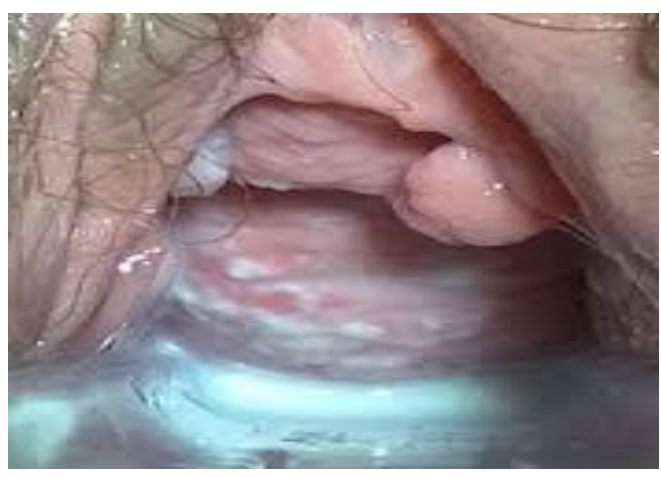


Fig.3 Growth of Difference Candida Species on CHROM agar

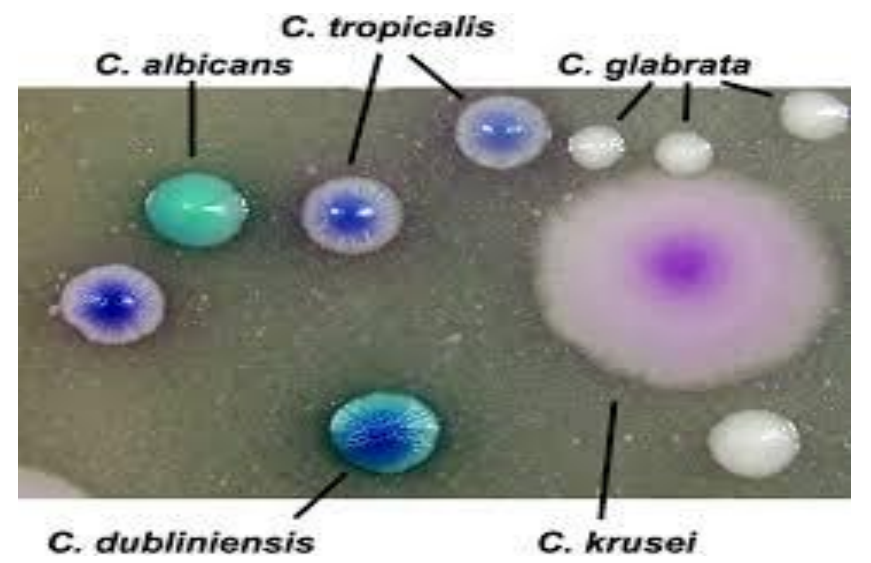

The microbiology of vulvovaginal candidosis in HIVpositive women seems to be identical to that of matched high-risk HIV-negative women, although with time and possible unmeasured azole exposure there is a tendency to isolate non-albicans Candida spp, notably $C$ glabrata and candida isolates with reduced sensitivity to fluconazole.

As with other forms of lower genital tract ulceration and infl ammation, vulvovaginal candidosis has been associated with enhanced vaginal HIV shedding and increased concentrations of HIV RNA in the genital tract. Hence, vulvovaginal candidosis might facilitate HIV transmission, although its contributory role is unknown. An argument can be made for treating asymptomatic and recurrent vulvovaginal candidosis in HIVpositive women in whom candida has been confi rmed by microscopy because of the associated enhanced HIV vaginal shedding. Such treatment should theoretically reduce the risk of transmission of HIV (Wang et al., 2001).

\section{References}

Al-Hedaithy, S.S. 2002. Spectrum and proteinase production of yeasts causing vaginitis in Saudi Arabian women. Med. Sci. Monit., 8: CR498-501.
Anis Ahmad, Asad U. Khan. 2009. Prevalence of Candida species and potential risk factors for vulvovaginal candidiasis in Aligarh, India. European J. Obstetrics \& Gynecol. Reproductive Biol., 144(1): 6871.

Bang, R.A., M. Baitule, S. Sarmukaddam, A.T. Bang, Y. Choudhary, O. Tale. 1989. High prevalence of gynaecological diseases in rural Indian women. The Lancet, 333(8629): $85-88$.

Bauters, T.G., Dhont, M.A., Temmerman, M.I., Nelis, H.J. 2002. Prevalence of vulvovaginal candidiasis and susceptibility to fl uconazole in women. Am. J. Obstet. Gynecol., 187: 569-74.

Berg, A.O., Heidrich, F.E., Fihn, S.D., et al. 1984. Establishing the cause of genitourinary symptoms in women in a family practice. Comparison of clinical examination and comprehensive microbiology. JAMA 1984; 251: 620-25.

Bertholf, M.E., Staffrd, M.J. 1983. Colonization of Candida albicans in vagina, rectum, and mouth. J. Fam. Pract., 16: 919-24.

Bhalla, P., Chawla, R., Garg, S., Singh, M.M., Raina, U., Bhalla, R., et al. 2007. Prevalence of a bacterial vaginosis among women in Delhi, India. Indian J. Med. Res., 125:167-72.

Buscemi, L., Arechavala, A., Negroni, R. 2004. Study of acute vulvovaginitis in sexually active adult women, with special reference to candidosis, in patients of the 
Francisco J Muniz Infectious Diseases Hospital.Rev Iberoam. Micol., 21: 17781.

Cauwenbergh, G. 1990. Vaginal candidiasis: evolving trends in the incidence and treatment of non-Candida albicans infection. Curr. Probl. Obstet. Gynecol. Fertil., 8: 241.

Centers for Disease Control and Prevention, CDC, Division of STD Prevention:www.cdc.gov/std.2010 CDC STD treatment guidelines.

Chander, J. Candidiasis. Textbook of Medical Mycology, third ed, New Delhi, Mehta Publishers, 266-290.

Chong, P.P., Lee, Y.L., Tan, B.C., Ng, K.P. 2003. Genetic relatedness of candida strains isolated from women with vaginal candidiasis in Malaysia. J. Med. Microbiol., 52: 657-66.

Corsello, S., Spinillo, A., Osnengo, G., et al. 2003. An epidemiological survey of vulvovaginal candidiasis in Italy. Eur. $J$. Obstet. Gynecol. Reprod. Biol., 110: 6672.

De Bernardis, F., Agatensi, L., Ross, I.K., et al. 1990. Evidence for a role forsecreted aspartate proteinase of Candida albicans in vulvovaginal candidiasis. $J$. Infect. Dis., 161: 1276-83.

Duerr, A., Heilig, C.M., Meikle, S.F., et al. 2003. Incident and persistent vulvovaginal candidiasis among human immunodeficiency virus-infected women: Risk factors and severity. Obstet. Gynecol., 101: 548-56.

Duguid, J.P. 2011. Staining Methods. In: J. G. Collee, A. G. Fraser, B. P. Marmion, A. Simmons. Mackie and McCartney Practical Medical Microbiology, 14th ed, New Delhi, Elsevier, 793.

Eckert, L.O., Hawes, S.E., Stevens, C.E., Koutsky, L.A., Eschenbach, D.A., Holmes, K.K. 1998. Vulvovaginal candidiasis: clinical manifestations, risk factors, management algorithm. Obstet Gynecol., 92: 757-65.

Esther Segal and Daniel Elad. Candidiasis. In: William G. Merz, Roderick J. Hay editors. Topley \& Wilsons Microbiology \& microbial infections, Medical Mycology, $10^{\text {th }}$ ed, Washington D.C :ASM press, Inc, 579-580.

Foxman, B., Marsh, J.V., Gillespie, B., Sobel, J.D. 1998. Frequency and response to vaginalsymptoms among white and African American women: results of a random digit dialing survey. J. Womens Health, 7: 1167-74.

Jack, D. Sobel. 2007. Vulvovaginal Candidosis. The Lancet, 369: 1961-1971.

Jack, D., Sobel, M.D. 1997. Vaginitis. N Engl. J. Med., 337: 1896-1903.

Jindal, N., Agarwal, A., Gill, P. 2006. Significance of Candida culture in women with vulvovaginal symptoms. J. Obstet. Gynecol. India, 56(2): 139-141.

King, R.D., Lee, J.C., Morris, A.L. 1980. Adherence of Candida albicans and other candida species to mucosal epithelial cells. Infect. Immun., 27: 667-74.

Mane, A., Gaikwad, S., Bembalkar, S., Risbud, A. 2012. Increased expression of virulence attributes in oral Candida albicans isolates from human immunodeficiency virus-positive individuals, J. Med. Microbiol., 61: 285290.

McCormack, W.M. Jr, Zinner, S.H., McCormack, W.M. 1994. The incidence of genitourinary infections in a cohort of healthy women. Sex Transm. Dis., 21: 63-64.

Naglik, J.R., Rodgers, C.A., Shirlaw, P.J., et al. 2003. Diff erential expression of Candida albicans secreted aspartyl proteinase and phospholipase $\mathrm{B}$ genes in humans correlates with active oral and vaginal infections. J. Infect. Dis., 188: 469-79.

Odds, F.C. 1988. Candidosis of the genitalia. Candida and candidosis. A review and bibliography. London, Philadelphia, Toronto, Sydney, Tokyo: Bailliere Tindall, 124.

Okungbowa, F.I., Isikhuemhen, O.S., Dede, A.P. 2003. The distribution frequency of Candida species in the genitourinary tract among symptomatic individuals in 
Nigerian cities. Rev. Iberoam. Micol., 20: 60-03.

Prasad, J.H., S. Abraham, K.M. Kurz. 2005. Reproductive tract infections among young married women in Tamil Nadu, India, International Family Planning Perspectives, 1(2): 73-82.

Schaller, M., Bein, M., Korting, H.C., et al. 2003. The secreted aspartyl proteinases Sap1 and Sap2 cause tissue damage in an in vitro model of vaginal candidiasis based on reconstituted human vaginal epithelium. Infect. Immun., 71: 3227-34.

Schuman, P., Sobel, J.D., Ohmit, S.E., et al. 1998. Mucosal candidal colonization and candidiasis in women with or at risk for human immunodeficiency virus infection. HIV Epidemiology Research Study (HERS) Group. Clin. Infect. Dis., 27: 1161-67.

Shah, D.T., Glover, D.D., Larsen, B. In situ mycotoxin production by Candida albicans in women with vaginitis. Gynecol Obstet. Invest., 39: 67-69.

Slutsky, B., Buffo, J., Soll, D.R. 1985. Highfrequency switching of colony morphology in Candida albicans. Sci., 230: 666-69.

Sobel, J.D., Myers, P.G., Kaye, D., Levison, M.E. 1981. Adherence of Candida albicans to human vaginal and buccal epithelial cells. J. Infect. Dis., 143: 76-82.

Sobel, J.D., Ohmit, S.E., Schuman, P., et al. 2001. The evolution of Candida species and fluconazole susceptibility among oral and vaginal isolates recovered from human immunodeficiency virus (HIV)seropositive and at-risk HIV-seronegative women. J. Infect. Dis., 183: 286-93.

Soll, D.R. 1988. High-frequency switching in Candida albicans and its relations to Vaginal candidiasis. Am. J. Obstet. Gynecol., 158: 997-1001.

Soll, D.R., Galask, R., Isley, S., et al. 1989. Switching of Candida albicans during successive episodes of recurrent vaginitis. J. Clin. Microbiol., 27: 681-90.

Taylor, B.N., Staib, P., Binder, A., et al. 2005. Profi le of Candida albicans-secreted aspartic proteinase elicited during vaginal infection. Infect Immun., 73: 1828-35.

Trama, J.P., Adelson, M.E., Raphaelli, I., Stemmer, S.M., Mordechai, E. 2005. Detection of Candida species in vaginal samples in a clinical laboratory setting. Infect. Dis. Obstet. Gynecol., 13: 63-67.

Trumbore, D.J., Sobel, J.D. 1986. Recurrent vulvovaginal candidiasis: vaginal epithelial cell susceptibility to Candida albicans adherence. Obstet. Gynecol., 67: 810-12.

Tsang, C. S. \& Samaranayake, L. P. Factors affecting the adherence of Candida albicans to human buccal epithelial cells in human immunodeficiency virus infection. Br. J. Dermatol., 141: 852858.

Wang, C.C., McClelland, R.S., Reilly, M., et al. 2001. The effect of treatment of vaginal infections on shedding of human immunodeficiency virus type 1 . J. Infect. Dis., 183: 1017-22.

\section{How to cite this article:}

Hodiwala Bhesania, A., and Narayankhedkar, A. 2017. Vulvovaginal Candidosis. Int.J.Curr.Microbiol.App.Sci. 6(1): 240-250. doi: http://dx.doi.org/10.20546/ijcmas.2017.601.029 